UDC $342.7+377$

LBC 67.400.3;74.47

\title{
QUALITY OF SECONDARY VOCATIONAL EDUCATION AS A GUARANTEE OF REALIZING THE CONSTITUTIONAL RIGHT TO SECONDARY VOCATIONAL EDUCATION
}

\author{
Mariya A. Zadorina \\ Ural State Law University, Ekaterinburg, Russian Federation
}

\begin{abstract}
Introduction: the paper is devoted to the study of the quality guarantees of secondary vocational education which are becoming fundamental nowadays because of professional personnel deficiency and the need to improve the system of vocational education. Methods: both the general scientific (analysis, synthesis, comparison) and specific legal methods of research (technical and legal, interpretation) are used. Results: the author defines the notion of the quality of secondary vocational education which is provided by the federal state educational standards set by the Constitution and acts as a guarantee of the constitutional right to vocational education. The author formulates the definition of the constitutional right to vocational education. The particular attention is paid to the definition of the role of quality guarantees of secondary vocational education in the system of guarantees of the constitutional right to secondary vocational education. The author proposes a classification of quality guarantees of secondary vocational education. Conclusions: the study shows that the guarantees of secondary vocational education quality originate in the Constitution of the Russian Federation, despite the fact that they are not directly specified in the constitutional provisions. It is found that the federal state educational standards enshrine temporal, competence, structural and resource guarantees of the quality of secondary vocational education.
\end{abstract}

Key words: quality of education, federal state educational standard, professional standard, the right to vocational education, guarantees of rights and freedoms.

УДК $342.7+377$

ББК $67.400 .3 ; 74.47$

\section{КАЧЕСТВО СРЕДНЕГО ПРОФЕССИОНАЛЬНОГО ОБРАЗОВАНИЯ КАК ГАРАНТИЯ РЕАЛИЗАЦИИ КОНСТИТУЦИОННОГО ПРАВА НА СРЕДНЕЕ ПРОФЕССИОНАЛЬНОЕ ОБРАЗОВАНИЕ}

\author{
Мария Андреевна Задорина \\ Уральский государственный юридический университет, г. Екатеринбург, Российская Федерация
}

\begin{abstract}
Введение: статья посвящена изучению гарантий качества среднего профессионального образования, которое в настоящее время приобретает основополагающее значение в связи с дефицитом профессиональных кадров и необходимостью совершенствования системы среднего профессионального образования. Методы: использованы общенаучные (анализ, синтез, сравнение) и специально-юридические методы исследования (технико-юридический, толкования). Результаты: автором раскрывается понятие качества среднего సे. профессионального образования, которое обеспечивается предусмотренными Конституцией Российской Федерации федеральными государственными образовательными стандартами и выступает гарантией конституционного права на среднее профессиональное образование. Предлагается авторское определение конституционного права на среднее профессиональное образование. Особое внимание уделяется определению места гарантий качества среднего профессионального образования в системе гарантий конституционного ల్ల права на среднее профессиональное образование. Автором предлагается классификация гарантий качества () среднего профессионального образования. Выводы: гарантии качества среднего профессионального обра-
\end{abstract}


зования берут свое начало в Конституции Российской Федерации, хотя прямо таковыми в ее положениях не называются. Установлено, что федеральные государственные образовательные стандарты закрепляют темпоральные, компетентностные, структурные и ресурсные гарантии качества среднего профессионального образования.

Ключевые слова: качество образования, федеральный государственный образовательный стандарт, профессиональный стандарт, право на среднее профессиональное образование, гарантии прав и свобод.

\section{Введение}

Конституция Российской Федерации [4], провозглашая права и свободы человека и гражданина высшей ценностью, признает их непосредственно действующими, придает им исходное значение и закрепляет основополагающие гарантии их реализации. Не является исключением и предусмотренное ч. 2 ст. 43 Конституции РФ право на среднее профессиональное образование, которое представляет собой конституционное субъективное право человека на приобретение квалификации рабочего, служащего, специалиста среднего звена, позволяющей осуществлять общественно полезную деятельность в соответствии с потребностями личности, общества и государства.

Так, ч. 5 ст. 43 Конституции РФ предусматривает федеральные государственные образовательные стандарты (далее - ФГОС), которые в соответствии с п. 6 ч. 1 ст. 2 Федерального закона от 29 декабря 2012 г. № 273-Ф3 «Об образовании в Российской Федерации» (далее-Федеральный закон об образовании) представляют собой «совокупность обязательных требований к образованию определенного уровня и (или) к профессии, специальности» [10]. Применительно к закрепленной в Конституции РФ возможности получения среднего профессионального образования такие требования устанавливаются федеральными государственными образовательными стандартами среднего профессионального образования (далее ФГОС СПО), которые разрабатываются отдельно по каждой профессии и специальности на основе профессиональных стандартов (при наличии), содержащих перечень требований к квалификации, необходимой для осуществления определенного вида профессиональной деятельности.

При этом и проекты ФГОС, и проекты профессиональных стандартов разрабатываются при участии представителей работодателей, что обеспечивает соответствие между подготовкой квалифицированных рабочих, служащих, специалистов среднего звена в образовательных организациях и требованиями работодателей к работникам с данным уровнем образования. Это обстоятельство обусловлено целями реализации конституционного права на среднее профессиональное образование, которые заключаются не только в повышении образовательного уровня населения, но и в подготовке профессиональных кадров для нужд отечественной экономики [2, с. 54].

Таким образом, заложенные в ФГОС требования к условиям реализации, структуре, объему и результатам освоения образовательных программ задают ключевые параметры качества образования, которое характеризуется соответствием подготовки обучающегося потребностям лиц (физических или юридических), в чьих интересах реализуется образовательная деятельность (ч. 3 ст. 11, п. 29 ч. 1 ст. 2 Федерального закона об образовании). Из этого следует, что ФГОС обеспечивают гарантии качества образования (п. 4 ч. 1 ст. 11 Федерального закона об образовании).

Более того, в содержании конституционного права на среднее профессиональное образование выделяют право на качество образования [2, с. 55], что позволяет рассматривать качество среднего профессионального образования как гарантию конституционного права на среднее профессиональное образование.

Между тем ни Конституция Российской Федерации, ни Федеральный закон об образовании не содержат понятия «качество среднего профессионального образования». Не раскрывается эта дефиниция и в иных нормативных правовых актах, регламентирующих особенности реализации конституционного права на среднее профессиональное образование. Однако обобщая отдельные законодательные положения, получается, что по смыслу ч. 1 ст. 2 , ч. $1,2,5$ ст. 11 , ч. 3 ст. 12 , ч. 1 ст. 68 Федерального закона об образовании качество среднего профессионального образо- 
вания можно определить как комплексную характеристику реализации образовательных программ среднего профессионального образования и подготовки квалифицированных рабочих, служащих, специалистов среднего звена, которая отражает степень их соответствия: ФГОС СПО; потребностям личности в углублении и расширении знаний, умений, навыков и компетенций в определенной сфере общественно полезной деятельности по той или иной профессии, специальности; потребностям работодателей в квалифицированных рабочих, служащих и специалистах среднего звена; запланированным результатам освоения образовательных программ среднего профессионального образования.

\section{Место гарантий качества среднего профессионального образования в системе гарантий конституционного права на среднее профессиональное образование}

Необходимо заметить, что проблемы гарантий качества среднего профессионального образования в юридической литературе мало изучены. Вместе с тем одной из первых гарантии качества образования как самостоятельный вид правовых гарантий конституционного права на высшее образование стала выделять И.Ф. Никитина, включая в их состав государственные образовательные стандарты, контроль за деятельностью вузов, лицензирование, аттестацию и аккредитацию вузов [5, с. 135-136]. Позднее идея гарантий качества образования нашла отражение в трудах И.В. Тяпкиной, которая рассматривает их как совокупность способов, приемов и методов охраны и обеспечения права на профессиональное образование [9, с. 116-117].

Тем не менее, хотя право на среднее профессиональное образование является относительно самостоятельной частью права на профессиональное образование [2, с. 55], в отношении гарантий качества среднего профессионального образования применить предложенный подход в полной мере не представляется возможным, так как он основан на нормах не действующего в настоящее время законодательства. Следует согласиться, что гарантии качества среднего профессионального обра- зования относятся к числу специальных (юридических) гарантий конституционного права на среднее профессиональное образование средств, мер и условий, способствующих непосредственной и правомерной реализации, охране и защите данного права. В свою очередь лицензирование и государственную аккредитацию образовательной деятельности следует отнести к организационным гарантиям - специально организованной деятельности органов государственной власти, общественных организаций и должностных лиц, направленной на эффективное использование общих и специальных гарантий конституционного права на среднее профессиональное образование.

Разделяя позицию Н.В. Витрука о делении специальных гарантий прав и свобод на гарантии реализации, гарантии охраны и защиты [1, с. 306], считаем возможным к гарантиям реализации конституционного права на среднее профессиональное образование отнести гарантии качества среднего профессионального образования, в состав которых и входят ФГОС СПО. При этом гарантии качества среднего профессионального образования необходимо отличать от гарантий охраны и защиты конституционного права на среднее профессиональное образование, к которым, в частности, относится государственный контроль (надзор) в сфере образования.

\section{Виды гарантий качества среднего профессионального образования}

Анализируя структуру и содержание ФГОС СПО, можно прийти к выводу, что заложенные в них требования берут свое начало в положениях Конституции Российской Федерации. Данную взаимосвязь можно проследить, если условно разделить гарантии качества среднего профессионального образования на темпоральные, компетентностные, структурные и ресурсные.

Темпоральные гарантии качества среднего профессионального образования исходят из положений Конституции РФ о поддержке различных форм образования и самообразования (ч. 5 ст. 43), праве на отдых (ч. 5 ст. 37). Они устанавливают временные характеристики процесса реализации конституционного 


\section{ТЕОРИЯ И ПРАКТИКА ГОСУДАРСТВЕННО-ПРАВОВОГО РАЗВИТИЯ}

права на среднее профессиональное образование: сроки обучения (в зависимости от профессии, специальности, формы обучения), объем учебной нагрузки, продолжительность каникул и т. д. Например, для лиц, имеющих среднее общее образование, при очной форме обучения период освоения профессии «Слесарь по ремонту автомобилей» составляет 10 месяцев [7], а для получения специальности «Юрист» - 1 год 10 месяцев [8]. Установленный ФГОС СПО срок получения образования вне зависимости от применяемых образовательных технологий по очной форме обучения не может быть уменьшен для лиц, имеющих среднее общее образование, что гарантирует реализацию конституционного права на данное среднее профессиональное образование в полном объеме.

Компетентностные гарантии качества среднего профессионального образования напрямую связаны с правом на труд, выбор рода деятельности и профессии (ч. 1 ст. 37 Конституции РФ). В основе данных гарантий лежит компетентностный подход к обучению, предполагающий сбалансированное сочетание осваиваемых студентом теоретических знаний и практических навыков [3, с. 191]. Компетентностные гарантии устанавливают область и объекты профессиональной деятельности выпускников, перечень компетенций, которыми должен овладеть обучающийся. Например, юрист базовой подготовки по специальности «Право и организация социального обеспечения» готовится к осуществлению двух видов деятельности, а юрист углубленной подготовки - четырех. Исходя из этого различается набор компетенций, которыми нужно овладеть. В частности, если юрист базовой подготовки должен научиться брать на себя ответственность за работу всей команды и результат совместных усилий, то юрист углубленной подготовки должен еще и уметь мотивировать, контролировать и организовывать работу членов команды [8].

Структурные гарантии качества среднего профессионального образования определяют структуру образовательной программы, разделяя ее на учебные циклы и разделы, устанавливая перечень обязательных для изучения дисциплин в целях предупреждения безработицы выпускников (что вытекает из ч. 3 ст. 37 Конституции РФ). В частности, помимо обязательной части образовательной программы ФГОС СПО предусматривают наличие вариативной части, которую образовательные организации разрабатывают сами с учетом потребностей регионального рынка труда для обеспечения конкурентоспособности выпускника, а следовательно, повышения его шансов на трудоустройство.

Ресурсные гарантии качества среднего профессионального образования определяют совокупность необходимых для реализации конституционного права на среднее профессиональное образование ресурсов в области кадрового, материально-технического, учебно-методического и иного обеспечения. Как видно, данный вид гарантий находится в тесной связи с гарантированным Конституцией правом на информацию (ч. 4 ст. 29), свободу преподавания (ч. 1 ст. 44), благоприятную окружающую среду (ст. 42) и т. д. Например, для реализации программ подготовки квалифицированных рабочих, служащих по профессии «Мастер по ремонту и обслуживанию автомобилей» обязательно наличие мастерских [7], а для программ подготовки специалистов среднего звена по специальности «Право и организация социального обеспечения» стрелкового тира [8].

\section{Выводы}

Качество среднего профессионального образования выступает одной из ключевых юридических гарантий реализации конституционного права на среднее профессиональное образование в полном объеме. Данные гарантии берут свое начало в Конституции РФ, хотя прямо таковыми в ее положениях не называются. Качество среднего профессионального образования обусловлено рядом факторов, в том числе соответствием подготовки обучающихся запросам работодателей. Основополагающей гарантией качества среднего профессионального образования выступают предусмотренные Конституцией РФ ФГОСы, которые закрепляют темпоральные, компетентностные, структурные и ресурсные гарантии качества.

В заключение добавим, что в настоящее время качество среднего профессионального 
образования приобретает особую важность в связи с дефицитом профессиональных кадров и необходимостью обновления системы среднего профессионального образования с учетом потребностей бизнеса и производства, о чем в своем послании Федеральному Собранию Российской Федерации в декабре 2016 г. заявил В.В. Путин [6].

\section{СПИСОК ЛИТЕРАТУРЫ}

1. Витрук, Н. В. Общая теория правового положения личности / Н. В. Витрук. - М. : Норма : Инфра-М, 2017. - 448 с.

2. Задорина, М. А. Конституционно-правовое содержание права на среднее профессиональное образование / М. А. Задорина // Вестник Волгоградского государственного университета. Серия 5, Юриспруденция. - 2016. - № 3 (32). - С. 54-59. DOI: https://doi.org/10.15688/jvolsu5.2016.3.7.

3. Иншакова, А. О. Компетентностный подход в учебно-методических комплексах юриста высшей школы / А. О. Иншакова, А. Я. Рыженков, Т. Л. Цыцылина // Вестник Волгоградского государственного университета. Серия 5, Юриспруденция. -2014. № 4 (25). - С. 191-194.

4. Конституция Российской Федерации : принята всенар. голосованием 12 дек. 1993 г. // Собрание законодательства РФ. - 2014. - № 31. - Ст. 4398.

5. Никитина, И. Ф. Конституционно-правовые основы высшего профессионального образования в Российской Федерации : дис. ... канд. юрид. наук / Никитина Инна Филипповна. - Екатеринбург, 2005. $-169 \mathrm{c}$.

6. Послание Президента РФ В.В. Путина Федеральному Собранию РФ от 1 дек. 2016 г. // Парламентская газета. - 2016. - 2-8 дек. (№ 45).

7. Приказ Министерства образования и науки РФ «Об утверждении федерального государственного образовательного стандарта среднего профессионального образования по профессии 23.01.17 Мастер по ремонту и обслуживанию автомобилей» от 9 дек. 2016 г. № 1581. - Доступ из справ.-правовой системы «КонсультантПлюс».

8. Приказ Министерства образования и науки РФ «Об утверждении федерального государственного образовательного стандарта среднего профессионального образования по специальности 40.02.01 Право и организация социального обеспечения от 12 мая 2014 г. № 508 : (с изм. и доп.) // Российская газета. - 2014. - 13 нояб. (№ 258/1).

9. Тяпкина, И. В. Правовой механизм реализации конституционного права на образование в средних и высших профессиональных учебных за- ведениях в России : дис. ... канд. юрид. наук / Тяпкина Ирина Вадимовна. - М., 2009. - 238 с.

10. Федеральный закон «Об образовании в Российской Федерации» от 29 дек. 2012 г. № 273-Ф3 : (с изм. и доп.) // Собрание законодательства РФ. 2012. - № 53 (ч. 1). - СТ. 7598.

\section{REFERENCES}

1. Vitruk N.V. Obshchaya teoriya pravovogo polozheniya lichnosti [The General Theory of Person's Legal Status]. Moscow, Norma Publ., INFRAM Publ., 2017.448 p.

2. Zadorina M.A. Konstitutsionno-pravovoe soderzhanie prava na srednee professionalnoe obrazovanie [Constitutional and Legal Content of the Right to Secondary Vocational Education]. Vestnik Volgogradskogo gosudarstvennogo universiteta. Seriya 5, Yurisprudentsiya [Science Journal of Volgograd State University. Jurisprudence], 2016, no. 3 (32), pp. 54-59. DOI: https://doi.org/10.15688/ jvolsu5.2016.3.7

3. Inshakova A.O., RyzhenkovA.Ya., Tsytsylina T.L. Kompetentnostnyy podkhod $\mathrm{V}$ uchebnometodicheskikh kompleksakh yurista vysshey shkoly [Competence Approach in Academic Textbooks of Lawyer in Higher School]. Vestnik Volgogradskogo gosudarstvennogo universiteta. Seriya 5, Yurisprudentsiya [Science Journal of Volgograd State University. Jurisprudence], 2014, no. 4(25), pp. 191-194.

4. Konstitutsiya Rossiyskoy Federatsii: prinyata vsenar. golosovaniem 12 dek. 1993 g. [The Constitution of the Russian Federation (Adopted by the Nation-Wide Voting on December 12, 1993)]. Sobranie zakonodatelstva RF [Collected Legislation of the Russian Federation], 2014, August 4 (no. 31), art. 4398.

5. Nikitina I.F. Konstitutsionno-pravovye osnovy vysshego professionalnogo obrazovaniya $v$ Rossiyskoy Federatsii: dis. ... kand. yurid. nauk [Constitutional and Legal Foundations of Higher Education in the Russian Federation. Cand. jurid. sci. diss.]. Ekaterinburg, 2005. 169 p.

6. Poslanie Prezidenta RF V.V. Putina Federalnomu Sobraniyu RF ot 1 dek. 2016 g. [Message by President of the Russian Federation V.V. Putin to the Federal Assembly of January 1, 2016]. Parlamentskaya gazeta, 2016, December 2-8 (no. 45).

7. Prikaz Ministerstva obrazovaniya i nauki $\mathrm{RF} \ll \mathrm{Ob}$ utverzhdenii federalnogo gosudarstvennogo obrazovatelnogo standarta srednego professionalnogo obrazovaniya po professii 23.01.17 Master po remontu i obsluzhivaniyu avtomobiley») ot 9 dek. 2016 g. № 1581 [The Order of the Ministry of Education and Science of the Russian Federation "On Approval of the Federal State Educational Standard of Secondary Vocational Education 


\section{ТЕОРИЯ И ПРАКТИКА ГОСУДАРСТВЕННО-ПРАВОВОГО РАЗВИТИЯ}

in the Profession 23.01.17 - Master for Repair and Maintenance of Vehicles of December 9, 2016 no. 1581]. Access from KonsultantPlyus reference legal system.

8. Prikaz Ministerstva obrazovaniya i nauki $\mathrm{RF} \ll \mathrm{Ob}$ utverzhdenii federalnogo gosudarstvennogo obrazovatelnogo standarta srednego professionalnogo obrazovaniya po spetsialnosti 40.02.01 Pravo i organizatsiya sotsialnogo obespecheniya ot 12 maya 2014 g. № 508: (sizm. i dop.) [The Order of the Ministry of Education and Science of the Russian Federation "On Approval of the Federal State Educational Standards of Secondary Vocational Education for Discipline 40.02.01 Law and Social Security Organization” of May 12, 2014 no. 508: (with amend. and. add.)]. Rossiyskaya gazeta, 2014, November 13 (no. 258/1).
9. Tyapkina I.V. Pravovoy mekhanizm realizatsii konstitutsionnogo prava na obrazovanie v srednikh $i$ vysshikh professionalnykh uchebnykh zavedeniyakh $v$ Rossii: dis. ... kand. yurid. nauk [Legal Mechanism of Realization of the Constitutional Right to Education in Secondary and Higher Professional Educational Institutions in Russia. Cand. jurid. sci. abs. diss.]. Moscow, 2009. 22 p.

10. Federalnyy zakon «Ob obrazovanii V Rossiyskoy Federatsii» ot 29 dek. 2012 g. № 273-FZ : (s izm. i dop.) [The Federal Law "On Education in the Russian Federation” of December 29, 2012, no. 273FL]. Sobranie zakonodatelstva RF [Collected Legislation of the Russian Federation], 2012, December 31, no. 53 (part 1), art. 7598 .

\section{Information about the Author}

Mariya A. Zadorina, Candidate for a Degree, Department of Constitutional Law, Ural State Law University, Komsomolskaya St., 21, 620137 Ekaterinburg, Russian Federation, zadorina@bk.ru.

\section{Информация об авторе}

Мария Андреевна Задорина, соискатель кафедры конституционного права, Уральский государственный юридический университет, ул. Комсомольская, 21, 620137 г. Екатеринбург, Российская Федерация, zadorina@bk.ru. 